\title{
Derechos Humanos: Desafíos presentes y futuros en Naciones Unidas
}

\author{
Heraldo Muñoz*
}

\section{Introducción}

La globalización ha proporcionado un nuevo contexto en el cual examinar el respeto por los derechos humanos y las libertades fundamentales. La globalización genera amenazas y oportunidades. Una de sus ventajas ha sido la expansión universal del valor de los derechos humanos y el consenso construido alrededor de un núcleo de derechos y libertades.

En general, se percibe que la integración internacional de los Estados mejora los derechos relativos a la seguridad, pero incrementa la desigualdad y amenaza los derechos sociales de los ciudadanos ${ }^{1}$. Pero la globalización ha creado nuevas oportunidades de desafiar al Estado "desde arriba y desde abajo", en las palabras de Richard Falk².

Un aumento en la conciencia y en el conocimiento de las violaciones de los derechos humanos es también un signo de los tiempos. Actualmente es prácticamente imposible mantener en secreto los casos de violaciones masivas de derechos humanos. A ello ha contribuido la difusión del uso de Internet y de cámaras personales de video capaces de reproducir imágenes que capturan, de modo incontrarrestable, la realidad de tales violaciones. Tampoco se puede dejar de mencionar el papel desempeñado por una red de activas organizaciones no gubernamentales, como Amnistía Internacional y Human Rights Watch, que están en la primera línea de defensa y promoción de los derechos humanos a escala mundial.

Como señala Roberto Garretón, el siglo XX deberá ser recordado como el siglo de los derechos humanos, ya que, pese a las graves violaciones a los derechos humanos que tuvieron lugar en ese periodo, este nos ha legado la formación progresiva de una cultura de los derechos humanos y su transformación en normas jurídicas vinculantes, que trasciende nacionalidad, religión y raza. Naciones Unidas ha sido uno de los instrumentos que ha ido creando esta cultura, a través de la lenta y difícil construcción de los consensos normativos. Pero no ha sido sólo su función normativa. También la comunidad de Estados ha adoptado resoluciones operativas que han acercado a "nosotros, los pueblos de las Naciones" a la Organización, por su compromiso con los derechos humanos ${ }^{3}$.

La función normativa fue complementada, de manera progresiva, a través de mecanismos de supervisión, como los "procedimientos especiales", destinados a examinar situaciones de países o asuntos temáticos y el procedimiento confidencial 1503.
* Embajador, Representante Permanente de Chile ante Naciones Unidos. El autor agradece la valiosa colaboración de Ignacio Llanos, Primer Secretario de la Misión Permanente de Chile ante Naciones Unidas, en la preparación de este artículo.

1 Introducción "Transnational Threats and Opportunities", en Globalization and Human Rights, Alison Brysk ed., Los Angeles: University of

California Press, 2002, p. 5.

2 Falk, Richard, "Interpreting the Interaction of Global Markets and Human Rights", en Globalization and Human Rights, Alison Brysk (ed.), Los Angeles, University of California Press, 2002, p. 61.

3 Garretón, Roberto, "La ONU y la Protección de los Derechos Humanos en Chile y América Latina" (II), Informe № 337, en Política Internacional, Santiago, 2003, pp. 2-3. www.asuntospublicos.org

Este comentario está disponible en: www.anuariocdh.uchile.cl 
4 Véase Donnelly, Jack, "Human Rights, Globalizing Flows, and State Power", en Globalization and Human Rights, Alison Brysk (ed.), Los Angeles: University of California Press, 2002, p. 228.

5 Citado en Coicaud, Jean-Marc et al., The Globalization of Human Rights, Tokyo, United Nations University Press, 2003, p. 1.
En este contexto, Naciones Unidas inició un proceso de reforma, coincidente con su $60^{\circ}$ aniversario, y que, en el área de los derechos humanos, ha derivado en el reemplazo de la Comisión de Derechos Humanos por un Consejo de Derechos Humanos y la introducción de un conjunto de medidas para superar los problemas que acompañaron al principal mecanismo de promoción y protección de estos derechos.

El principal hito de este proceso ha sido la creación por parte de la Asamblea General, el pasado 15 de marzo, del Consejo de Derechos Humanos. Este nuevo órgano reemplaza a la Comisión de Derechos Humanos, la cual perdió credibilidad, puesto que acogía como miembros a países que utilizaban su membresía para atacar a otros países, o bien, para defenderse de las críticas que se les hacían.

En el presente artículo se postula que el respeto de los derechos humanos exige que, más allá de la elaboración de estándares de derechos humanos, se enfatice la implementación de los mismos, lo cual debería contemplarse en cualquier ejercicio de reforma. Asimismo, se describen las etapas de la negociación que condujo al establecimiento del Consejo de Derechos Humanos, los rasgos principales de este nuevo órgano, así como sus perspectivas.

\section{La implementación de los estándares de derechos humanos}

La Declaración Universal de los Derechos Humanos (1948), el Pacto Internacional de Derechos Civiles y Políticos y el Pacto Internacional de Derechos Económicos, Sociales y Culturales, establecieron el significado de los derechos humanos en la sociedad internacional contemporánea ${ }^{4}$. Ellos han Ilegado a ser aceptados como el estándar mínimo para evaluar el cumplimiento de todo Estado con respecto a tales derechos.

La implementación de los estándares de derechos humanos es menos un problema de contar con estándares internacionales que de cumplir tales estándares. Nos encontramos aquí con un problema: la falta de consecuencias para el Estado por el incumplimiento de los estándares internacionales de derechos humanos. La ratificación universal de los instrumentos de los citados derechos, así como el retiro de las reservas formuladas a los mismos son tareas aún pendientes.

Como ha declarado el Secretario General de Naciones Unidas: "Existe una grave tensión entre los cada vez más influyentes principios globales, por una parte, y la dificultad práctica, en la otra, de implementarlos por parte de Estados renuentes a acatar los principios de derechos humanos o a comprometer los recursos requeridos para dar a esos principios un efecto imparcial y general cuando ellos son violados ${ }^{\prime \prime}$.

En general, la maquinaria internacional de implementación ha sido débil y abierta a influencias políticas. Un ejemplo es lo que ocurría con la Comisión de Derechos Humanos. Alrededor de un tercio de los miembros de este órgano estaba compuesto por Estados que a todas luces se encontraban entre los peores violadores de los derechos humanos. 
Además, las reglas de Naciones Unidas no contemplaban mecanismos

6 Doc. $\mathrm{A} / 59 / 2005$. para bloquear el acceso a tales Estados a la presidencia de la Comisión, exhibiendo así una de las mayores paradojas en el sistema internacional de protección de los derechos humanos.

El enfatizar la implementación no quiere decir que se deba excluir la elaboración creativa de estándares en áreas donde existan claros vacíos y el desarrollo de nuevas instituciones. Y aquí vale la pena traer a colación un caso que debería ser tratado por juristas: ¿Cómo hacer efectiva la responsabilidad de los actores no-estatales, como los señores de la guerra presentes en numerosos conflictos? Contamos en la actualidad con una maquinaria internacional de derechos humanos que sólo considera al Estado como posible violador de los derechos humanos. ¿Quién, entonces, será el responsable en un territorio en el cual el Estado no ejerce un control efectivo?

Para introducir una medida de gobernabilidad a los derechos humanos se requiere un rol activo del Estado, tanto con respecto a los derechos civiles y políticos como también respecto de los derechos económicos, sociales y culturales. Este enfoque -que puede ser enmarcado como una acción de gobernabilidad "desde dentro" - tiene la ventaja de dar a los Estados una nueva oportunidad para abordar las cuestiones internas de derechos humanos, demandándoles tomar acciones positivas para hacer valer estos derechos.

El énfasis en la implementación debe ser parte del proceso de reforma institucional de la maquinaria de promoción y protección de los derechos humanos.

\section{La reforma de Naciones Unidas}

Por primera vez en mucho tiempo se ha abierto una "ventana de oportunidad" para reformar Naciones Unidas. A diferencia de esfuerzos pasados al interior de la ONU, que no lograron avanzar en propuestas innovadoras de cambio y no pudieron superar las diferencias, la ambiciosa propuesta de Kofi Annan, basada en un informe previo de un panel de personalidades, ha generado un intenso debate, así como esperanzas de que, esta vez, se realizará el aggiornamento pendiente de la Organización.

En su informe, "Un concepto más amplio de la libertad: desarrollo, seguridad y derechos humanos para todos" ${ }^{\prime 6}$, el Secretario General propone reformas en las áreas de trabajo clave de la organización: el desarrollo, la seguridad y los derechos humanos.

En materia de derechos humanos, el Secretario General propuso sustituir la Comisión de Derechos Humanos por un Consejo de Derechos Humanos, de composición más reducida, situado preferentemente a nivel de órgano principal, lo cual constituye una las proposiciones más innovadoras y de mayor impacto potencial. Sus integrantes serían elegidos por mayoría calificada en la Asamblea General y se comprometerían a acatar las normas más rigurosas respecto de los derechos humanos. Se 
7 Este concepto fue recogido en el Documento Final de la Reunión Plenaria de Alto Nivel como "Responsabilidad de proteger a las poblaciones del genocidio, los crímenes de guerra, la depuración étnica y los crímenes de lesa humanidad" (párrs. 138 a 140$)$.

8 A/60/L.1* pretendía así enfrentar una de las críticas más serias hechas a la Comisión de Derechos Humanos, de 53 miembros, que muchos países buscaban integrarla para protegerse de críticas o para criticar a otros, lo cual derivó en la pérdida de credibilidad del órgano.

El diseño propuesto por el Secretario General incluye, junto a la Asamblea General, un sistema de tres Consejos: el Consejo de Seguridad, el Consejo Económico y Social y el nuevo Consejo de Derechos Humanos.

El informe postula que la democracia es un derecho universal. En este contexto, el Secretario General cita a la Comunidad de Democracias, presidida por Chile al momento de la publicación del informe, como ejemplo de las iniciativas internacionales en materia de promoción universal de la democracia. El Secretario General propuso la creación de un Fondo para la Democracia en Naciones Unidas -ya constituidocon el objeto de prestar asistencia a los países que desean establecer o fortalecer sus democracias.

El informe hace suya la tesis jurídica, aún en formación, de la existencia de una "responsabilidad internacional colectiva de proteger", en caso de que las autoridades nacionales no estén dispuestas a defender a sus ciudadanos o no puedan hacerlo, como en caso de violaciones masivas a los derechos humanos o de depuración étnica. Se trata de una "obligación internacional". La responsabilidad de proteger recae primera y primordialmente en cada uno de los Estados y, en caso de insuficiencia, ella debe ser ejercida por el Consejo de Seguridad. Chile apoyó este enfoque, junto a un grupo de países que conforman la Red de Seguridad Humana en Naciones Unidas ${ }^{7}$.

Un punto importante de la propuesta del Secretario General es que insinúa una transacción, donde los países ricos ayuden a que los pobres se desarrollen, en tanto estos últimos colaboren con los ricos para reducir sus temores en materia de seguridad. Además, la propuesta de Kofi Annan es amplia y ha sido planteada como un paquete integral de reformas de todo el sistema, una suerte de single undertaking.

\section{Hacia un nuevo Consejo de Derechos Humanos}

La decisión de crear el Consejo de Derechos Humanos es uno de los grandes logros del Documento Final de la Reunión Plenaria de Alto Nivel, el cual se basó en las propuestas del Secretario General, aunque la implementación real de este acuerdo exigió arduas negociaciones adicionales entre los miembros de Naciones Unidas ${ }^{8}$.

Ante la virtual imposibilidad de llegar a acuerdo en el plazo disponible durante las negociaciones de la Asamblea General, el entonces Presidente de la Asamblea General, el gabonés Jean Ping, decidió arbitrar una propuesta respecto del Consejo de Derechos Humanos. Esta consistió en presentar en una sección del documento un conjunto de párrafos que enuncian los rasgos básicos del futuro Consejo de Derechos Humanos, incluyendo la decisión de crear el mismo. 
Estos son:

152. De conformidad con nuestro compromiso de reforzar aún más los mecanismos de derechos humanos de las Naciones Unidas, decidimos establecer un Consejo de Derechos Humanos.

153. El Consejo será responsable de promover el respeto universal de la protección de todos los derechos humanos y libertades fundamentales para todas las personas, sin distinciones de ningún tipo y de forma justa y equitativa.

154. El Consejo deberá abordar las situaciones en que se violen los derechos humanos, incluidas las violaciones graves y sistemáticas, y hacer recomendaciones al respecto. También deberá promover la coordinación eficaz y la incorporación de los derechos humanos en el sistema de las Naciones Unidas.

55. Pedimos al Presidente de la Asamblea General que Ileve a cabo negociaciones abiertas, transparentes e inclusivas que concluyan lo antes posible durante el sexagésimo período de sesiones con objeto de establecer el mandato, las modalidades, las funciones, el tamaño, la composición, los miembros, los métodos de trabajo y los procedimientos del Consejo.

Los párrafos transcritos, si bien dieron satisfacción a la aspiración de la gran mayoría de países miembros de Naciones Unidas de crear un Consejo de Derechos Humanos, no recogieron algunas propuestas interesantes planteadas en el curso de las negociaciones ${ }^{9}$. Sin embargo, debe aclararse que ello sólo puede ser atribuido a la actitud de una minoría de una docena de países que, en forma sostenida, se opuso a cualquier avance en esta área, bajo el pretexto de buscar evitar la politización y selectividad en el trabajo del nuevo órgano.

El documento final de reforma, incluyendo la creación inicial del Consejo, fue refrendado por los 170 Jefes de Estado y de Gobierno asistentes a la Cumbre de Naciones Unidas, erigiéndose en un verdadero "mapa de ruta" de la reforma de la organización.

En cumplimiento del mandato dado al Presidente de la Asamblea por el párrafo 155 ya mencionado, éste convocó a los países miembros, a partir de octubre de 2005, a una serie de consultas sobre los principales aspectos del Consejo de Derechos Humanos, con el propósito de contar con una resolución de la Asamblea General aprobada antes del 31 de diciembre de 2005. Estas abordaron aspectos tan variados como el estatus, tamaño, composición y membresía; mandato y funciones, y las reglas de procedimiento, métodos de trabajo y arreglos de transición relativos al Consejo.

En estas negociaciones, Chile postuló un Consejo de Derechos Humanos de carácter permanente, que pudiera sesionar durante todo el año y reaccionar frente a cualquier situación urgente que afecte a los derechos humanos. Este órgano debía situarse en el nivel de órgano principal de Naciones Unidas, como una manera de dar coherencia a la prioridad
9 Como, por ejemplo, la propuesta de hacer recomendaciones de política a la Asamblea General, el Consejo de Seguridad, el ECOSOC y otros órganos de Naciones Unidas y la que describía al Consejo como el "órgano primariamente responsable" de la promoción y protección de los derechos humanos. 
${ }^{10}$ Los Representantes Permanentes de Panamá y Sudáfrica.

11 Doc. A/RES/60/251. que tienen los derechos humanos en Naciones Unidas, junto con la seguridad y el desarrollo. Si ello no fuera posible, afirmamos que aceptábamos un Consejo que fuera órgano subsidiario de la Asamblea General, siempre que pudiera revisarse después de un tiempo su eventual transformación en un órgano principal.

Nuestro país sostuvo que el mandato del Consejo de Derechos Humanos debía ser fuerte, de manera de poder tratar cualquier materia relativa a la promoción y protección de todos los derechos humanos.

Asimismo, Chile apoyó las propuestas destinadas a hacer frente a las críticas de politización y falta de credibilidad de la Comisión de Derechos Humanos. Para ello era necesario hacer más difícil que países que violan los derechos humanos Ileguen a ser miembros del órgano encargado, precisamente, de velar por la promoción y protección de los derechos humanos. Para abordar este problema nuestro país postuló que los miembros del Consejo debían ser elegidos por un quórum alto (2/3 de la Asamblea General), en un órgano cuyo tamaño debía ser algo más reducido que el de la Comisión de Derechos Humanos de 53 miembros (propusimos un rango de entre 40 a 53 miembros). Asimismo, los integrantes del nuevo órgano debían estar dispuestos a asumir el compromiso de guiarse por los más altos estándares de derechos humanos y estar dispuestos a someterse a un mecanismo de revisión entre pares. Como veremos, el Consejo aprobado es de composición más reducida (47 miembros) y ellos deberán ser elegidos por mayoría absoluta en la Asamblea General.

\section{Votación de la resolución}

Luego de intensas negociaciones lideradas por el Presidente de la Asamblea General, Jan Eliasson (Suecia), asistido por dos facilitadores ${ }^{10}$, a mediados de marzo de 2006 éste presentó un proyecto de resolución, el cual fue descrito como "texto de compromiso". Este fue percibido por una gran mayoría de países como el mejor resultado posible de obtener. La opción de reabrir el "paquete", como deseaba Estados Unidos, amenazaba con romper el equilibrio interno del proyecto. La postergación de las negociaciones tampoco permitía vislumbrar un resultado mejor. Un grupo de embajadores alentó al Presidente de la Asamblea General a presentar el texto, asumiendo el riesgo de una votación cuyo resultado no era del todo previsible.

El texto fue sometido a la votación de la Asamblea General el 15 de marzo de 2006, la cual lo aprobó por una abrumadora mayoría de 170 votos a favor, 4 en contra (Estados Unidos, quien pidió la votación, Israel, Islas Marshall y Palau), y tres abstenciones (Venezuela, Irán y Belarús $)^{11}$.

Ciertamente, es de lamentar que Estados Unidos se haya opuesto a la adopción por consenso de una resolución que había sido bien acogida por numerosos sectores, incluyendo países que promovían un Consejo de Derechos Humanos fuerte, así como por prestigiosas organizaciones 
no gubernamentales como Amnistía Internacional y Human Rights Watch. En su explicación de voto el día de la adopción de la resolución, la delegación de Estados Unidos sostuvo que, en ausencia de mecanismos más fuertes para mantener una membresía con credibilidad, no podía sumarse al consenso. Sin embargo, afirmó que cooperaría con otros Estados miembros para que el Consejo "sea tan fuerte y efectivo como pueda serlo".

\section{Principales aspectos del Consejo, según la resolución 60/251}

Estatus. Se decidió establecer el Consejo de Derechos Humanos, con sede en Ginebra, como órgano subsidiario de la Asamblea General. La Asamblea revisará el estatus del Consejo dentro de cinco años. Se trata de una fórmula de compromiso que deja abierta la posibilidad de que el Consejo se transforme en un órgano principal.

Mandato y funciones. El Consejo será responsable de promover el respeto universal por la protección de todos los derechos humanos y libertades fundamentales de todas las personas, sin distingos de ningún tipo y de una manera justa y equitativa. Entre las funciones adoptadas figuran la de ocuparse de las situaciones en que se violen los derechos humanos, incluidas las violaciones graves y sistemáticas, y hacer recomendaciones al respecto. También deberá prevenir las violaciones de los derechos humanos; responder a las situaciones de emergencia en materia de derechos humanos; servirá como foro de diálogo sobre cuestiones temáticas relativas a todos los derechos humanos; hará recomendaciones a la Asamblea General para seguir desarrollando el derecho internacional en el área de los derechos humanos; promoverá la coordinación de los derechos humanos en el sistema de Naciones Unidas; y mantendrá un sistema de procedimientos especiales.

Mecanismo de examen periódico universal (peer review mechanism). Esta es una de las principales innovaciones con respecto al mandato de la Comisión. El Consejo realizará un examen periódico universal sobre el cumplimiento por cada Estado de sus obligaciones y compromisos en materia de derechos humanos. Se trata que este mecanismo complemente y no duplique la labor de los órganos creados en virtud de tratados, como el Comité de Derechos Humanos.

Tamaño, composición y membresía. El Consejo estará integrado por 47 Estados Miembros que serán elegidos de manera directa en votación secreta por la mayoría (absoluta) de los 191 miembros de la Asamblea General. Su composición estará basada en una distribución geográfica equitativa. Los puestos se distribuirán entre los grupos regionales de la manera siguiente: Grupo de Estados de África: 13; Grupo de Estados de Asia: 13; Grupo de Estados de Europa Oriental: 6; Grupo de Estados de América Latina y el Caribe: 8; Grupo de Estados de Europa Occidental y otros Estados: 7. El mandato de los miembros durará tres años y no podrán postular a la reelección inmediata después de dos períodos consecutivos. 
12 Los compromisos de los candidatos pueden ser consultados en http://www.un.org/ga/ 60/elect/hrc/
Criterios de membresía. En definitiva, no se establecieron criterios estrictos para participar en el Consejo. Como contrapartida se prevé que los elegidos al Consejo deberán defender "Ias más altas exigencias en la promoción y protección de los derechos humanos, cooperar plenamente con el Consejo y ser examinados con arreglo al mecanismo de examen periódico universal durante su período como miembros".

Promesas y contribuciones. La resolución contiene una importante exhortación ética y política a los Estados para que al elegir a los componentes del Consejo, éstos tengan en cuenta la contribución de los candidatos a la promoción y protección de los derechos humanos y las promesas y contribuciones voluntarias que hayan hecho al respecto. Con miras a la primera elección de los miembros del Consejo de Derechos Humanos, diversos Estados presentaron compromisos explícitos, lo cual no tiene precedentes en la Comisión de Derechos Humanos. Entre los compromisos asumidos pueden citarse la ratificación de instrumentos de derechos humanos, el retiro de reservas a los mismos, presentación de informes a órganos de tratados, la creación de instituciones (Ombudsman), adopción de planes nacionales (como, por ejemplo, contra el racismo), invitaciones permanentes a procedimientos especiales, apoyo político a iniciativas, etc. ${ }^{12}$

Suspensión. Se prevé que la Asamblea General, por mayoría de dos tercios de los miembros presentes y votantes, pueda suspender los derechos de miembro de todo integrante del Consejo que cometa violaciones graves y sistemáticas de los derechos humanos.

\section{Conclusiones}

El sistema de promoción y protección de los derechos humanos en Naciones Unidas ha experimentado un desarrollo progresivo a través de las últimas seis décadas.

La globalización ha generado amenazas y oportunidades para los derechos humanos. Una de sus ventajas ha sido la globalización del valor de los derechos humanos y un nuevo consenso en torno a ciertos derechos básicos. Ella ha traído consigo un positivo aumento de la conciencia y conocimiento en materia de violación de estas prerrogativas.

Se requiere, además, un énfasis en la implementación para así promover la aplicación de los estándares internacionales de derechos humanos ya acordados, en lugar de continuar privilegiando la actividad de elaboración de estándares.

El proceso de reforma de Naciones Unidas tiene como uno de sus pilares a los derechos humanos, junto con la seguridad y el desarrollo. El Secretario General de Naciones Unidas propuso la creación de un nuevo Consejo de Derechos Humanos en reemplazo de la Comisión de Derechos Humanos, iniciativa que fue acogida por los Jefes de Estado y de Gobierno en la Reunión Plenaria de Alto Nivel de la Asamblea General y que hoy se ha tornado en realidad. 
La creación del Consejo de Derechos Humanos es uno de los grandes logros de la reforma de Naciones Unidas y desde ya es considerada una institución emblemática surgida de este proceso. Existe consenso en que el Consejo de Derechos Humanos representa una mejoría considerable con respecto a la Comisión de Derechos Humanos. Pese a ello, existen importantes aspectos pendientes de negociación por el propio Consejo, de cuya configuración final dependerá, en gran medida, la observancia de los derechos humanos en el siglo XXI. 